\title{
Application of vitual instrument for Tank Integrated Simulator Based-on LabWindows/CVI
}

\author{
Xue Qing ${ }^{1}$, Luo Jia ${ }^{1}$, Zheng Changwei ${ }^{1}$,Wang Wei ${ }^{2}$, Huang Yibin ${ }^{1}$ \\ 1. Department of Equipment Command and Manage, Academy of Armored Force Engineering, Beijing, China, 100072 \\ 2. Beijing Institute of Special Vehicle, Beijing, China, 100072
} 13811772060@163.com

\begin{abstract}
The tank detection display system is an basic component of the tank integrated simulator. This paper describes the design process of virtual instrument for tank integrated simulator based on LabWindows/CVI. The hardware architecture and diagrams of system are introduced first. The software module architecture and design development process are given later. The research of several key issues is focused on, such as signal collection 、 communication in TCP model control of operation load system as well as parameters tests in automatic condition. And finally practical interface images of tank virtual instruments which give a powerful technical support for detection and maintenance are achieved so that met the demands for training purpose.
\end{abstract}

Keywords-LabWindows/CVI, virtual instrument, tank integrated simulator, data collection

\section{INTRODUCTION}

With the changes in military demand and the application of computer technology which is developing so fast, there is a number of increasing in the complexity and informational level of the tank information and control system; therefore, the use of tank integrated simulator especially with the operation training of digitized weapons and equipment which has become an indispensable part in the construction of armored force during recent years. Virtual instruments based-on LabWindows/CVI are important part of integrated simulator, have characteristics about high effectiveness and low costing.

\section{SYSTEM STRUCTURE}

The computer network technique and theory of system simulation are used for the simulator. And this simulator has the basic practicing functions including communication drive , and command which can satisfy the demands for army. This system made by LabWindows/CVI is not only the window that displays the virtual instruments and performance parameters, but also a key basis for the crew to give a reasonable judgment and a correct manipulation in response to a wide circumstances range. The figure of control system for tank integrated simulator is showed below:

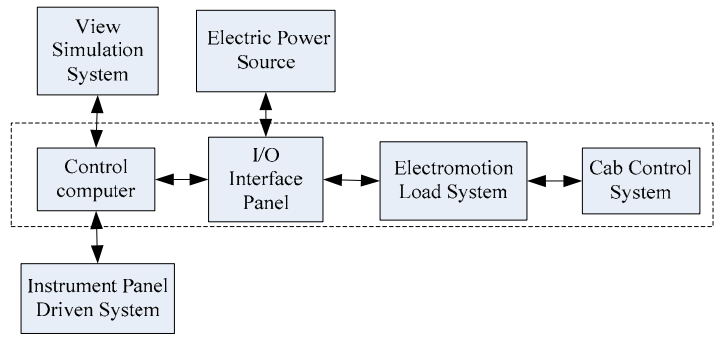

Figure 1. Framework for Simulator Control System

\section{A. Simulation System for Control and Operation}

Control and operation is the key issue used to afford cab operation sense realistically, which is also called operation load system. Cab operation sense is made for tank moving to the crew, mainly controlled by driver inputting actions to the simulator. Simulation system for control and operation is divided into two parts. One is hydraulic pressure system of tank cab, another is main console.

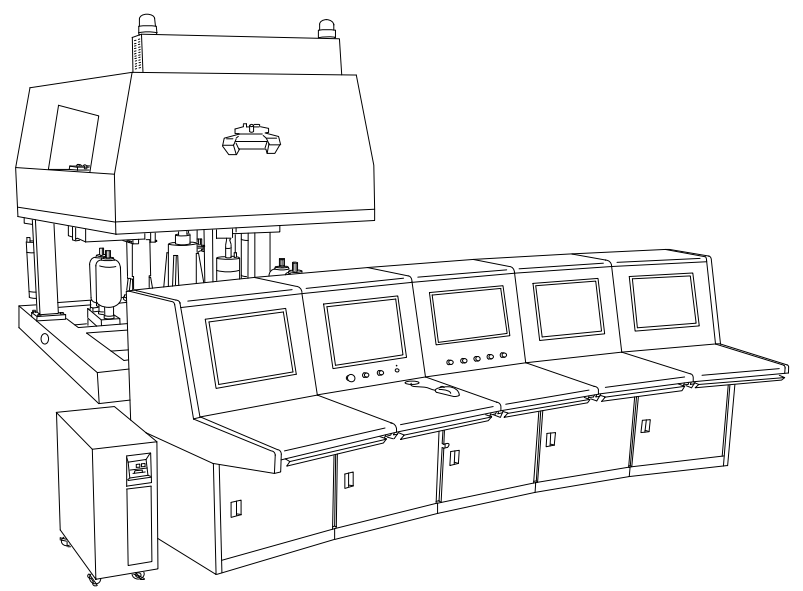

Figure 2. Hydraulic pressure system of tank cab and main console

Hydraulic pressure system of tank cab is used for special tank practice such as communication 、driving and shooting. It can simulate different postures when tank is moving on different terrains, and it is the base of main console which can display, control and dictate messages for commander、 instructor driver and gunner represented by computers is the brain of all the simulation systems. 


\section{B. Control system of simulative instrument}

Control system of simulative instrument is the important part of tank simulator. This system can afford and present different kinds of panel data in different situations controlled with varies dictations made by commander or instructor. The instruments used by the simulator are as true as the counterparts in real tank and the cab structure is strictly designed vivid. Different postures supplied by hydraulic pressure system can imitate real tank positions such as shooting , driving in different terrains.

\section{View simulation system}

This system is made up by core parts: one is image process software system. High resolving capability images are processed by this system, and source-files are cut up by multi-channel 、 illumination adjust 、 verge congregation regulating 、 overlapping , and handling vague. The other one is multi-channels output system which can represent clear pictures to the crews including gunner、 commander and driver at the same time after accepting pictures dealt with the image processing system.

The whole system simplifies the controlling process based-on functions and convenience that confirms the practice qualifies.

\section{Structure design of system hardware}

The core part of tank simulation is main console. All the simulator working signals are coming from operation load system which is composed by hydraulic pressure system and tank operation system mentioned above. The actions made by operators let brake、 clutch and other control devices moving measured by sensors, computers in main console analyze signals and transport them by Ethernet each other whose screen would show images corresponding with the actions. And console delivers analyzed signals by Adam to the instruments embedded in cab in real-time.

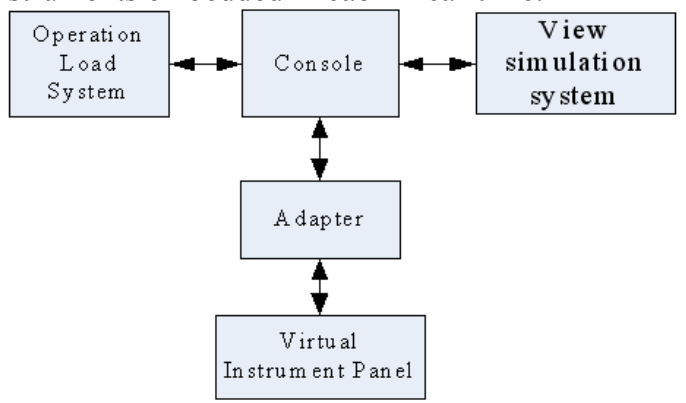

Figure 3. Structure design of system hardware

\section{IMPLEMENT OF SOFTWARE BASED-ON LABWINDOWS/CVI}

\section{A. Introduction above LabWindows/CVI}

LabWindows/CVI is a mutual development software to face process of virtual instruments and test. It combines $\mathrm{C}++$ language with special test tool. The software has powerful hardware control and signal analyzed capability fit for develop software about measure v control and error analyze. The software packages for database and network are added to LabWindows/CVI which satisfied the demands of high capacity data storage and distributed long-distance network test system.

Considering the advantages mentioned above and all the running signals coming from operation load system, choose LabWindows/CVI as the software development tool.

\section{B. Design of system software}

\section{1) Design of software structure and module}

Based-on modularize and structure thought, the system software is divided into three modules: signal collecting, controlling and assistance showed as below:

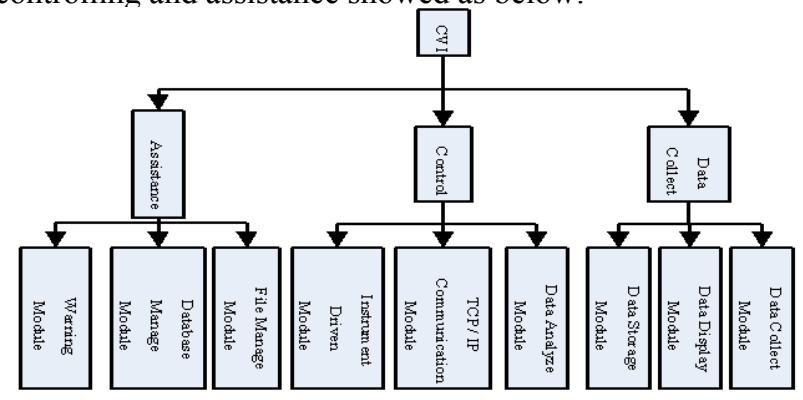

Figure 4. Software structure based-on LabWindows/CVI

Software is designed by LabWindows/CVI, there is flow chart:

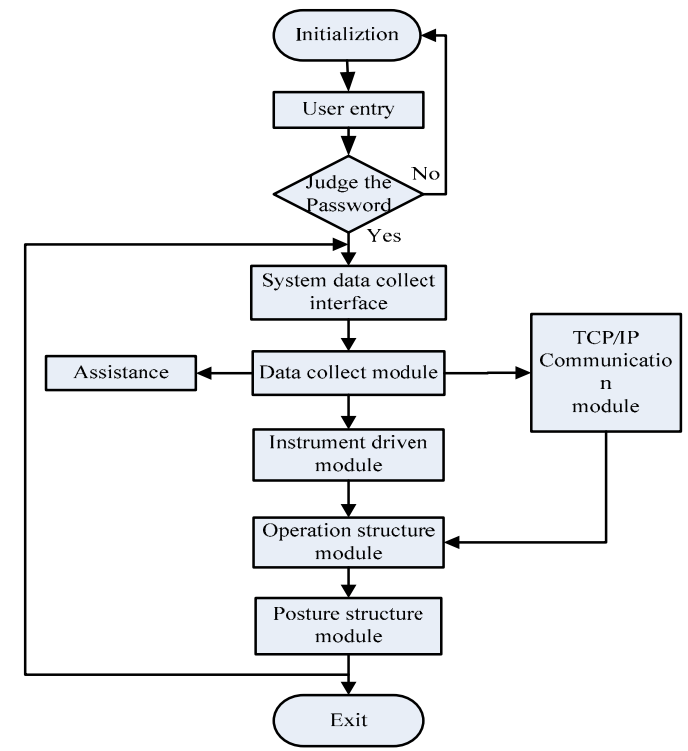

Figure 5. software development flow chart

\section{Key modules of software programming}

2) Posture control module:

Function: int ComWrt(int COMPot, char buffer[ ],int count) //sends control orders to transducer by serial interface COMPort, order data are storaged in memory buffer[ ],data length is count byte. 
Transfer: ComWrt (RS485_COM, run_code, 8); //running

ComWrt (RS485 COM, up code, 8);//front whirl

ComWrt（RS485_COM, down_code, 8);//reverse whirl

ComWrt（RS485_COM, stop_code, 8);//stop

Function: void CRC_WrtFre ( int FRECOM , unsigned int DValue, unsigned FreAdr, int Length_CRC) set working frequency of transducer, send working frequency value Dvalue to transducer by serial interface FRECOM.

3) operation structure module:

Function: double sensor com(int ID);//set reading order to sensor, read and storage sensor original data, compute displacement.

method: ( Rdata[3]-ASCII 0 ) $\times 100+$ ( Rdata[4]ASCII_0 $) \times 10+($ Rdata[5]-ASCII_0 $)+($ Rdata[6]ASCII 0) $\times 0.1$

Panel driven control module:

Function: void da_send ( int com, int kahao, int channel, double da senddata) //send needed voltage value.

Function: double AD24 (int COM, int CardID, int way, double*Val) //collect voltage and show it on panel.

Function: void Relay ( int comport, int cardID, intchanelNum, char ctrldata[17]) //control relay situation.

4) View control module:

Function: void calculate ( ) //compute $\mathrm{x}, \mathrm{y}$ and $\mathrm{z}$ coordinates with accelerator pedal and brake pedal;

Function: void (*InitNet $) \quad($ int flg $)$ //initialize network

Function: void (*SendFlightData ) ( int flg )//send signals to view computer.

\begin{tabular}{|c|c|c|c|c|c|c|c|c|c|}
\hline \multicolumn{2}{|c|}{ This _time_exarine__escult } & \multicolumn{8}{|c|}{ 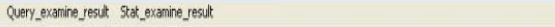 } \\
\hline ID & name & compary & plation & squad & score & grade & year & month & day \\
\hline 67 & & 1 & 1 & 1 & 5 & Excelence & 2007 & 10 & 7 \\
\hline 68 & & 1 & 1 & 1 & 1 & Nopass & 2007 & 10 & 7 \\
\hline 69 & & 1 & 1 & 1 & 0 & Nopass & 2007 & 10 & 7 \\
\hline 70 & & 1 & 1 & 1 & 1 & Nopess & 2007 & 10 & 7 \\
\hline 71 & & 1 & 1 & 1 & 0 & Nopass & 2007 & 10 & 8 \\
\hline 72 & & 1 & 1 & 1 & 0 & Nopass & 2007 & 10 & 11 \\
\hline 73 & & 1 & 1 & 1 & 0 & Nopess & 2007 & 10 & 11 \\
\hline 74 & & 1 & 1 & 1 & 0 & Nopass & 2007 & 10 & 11 \\
\hline 75 & & 1 & 1 & 1 & 1 & Nopass & 2007 & 10 & 11 \\
\hline 76 & & 1 & 1 & 1 & 0 & Nopess & 2007 & 10 & 23 \\
\hline 77 & & 1 & 1 & 1 & 0 & Nopesss & 2007 & 10 & 23 \\
\hline 78 & & i & $i$ & $i$ & 5 & Excelence & 2007 & 10 & 23 \\
\hline 79 & & $i$ & $i$ & $i$ & 0 & NoPass & 2007 & 10 & 23 \\
\hline
\end{tabular}

Figure 6. main interface of system testing



Figure 7. Hydraulic Management System Interface

\section{CONCLUSION}

Virtual instruments are not only essential component of the tank integrated simulator, but also a necessary condition for the realization of the training purpose. The simulation method used by the system is efficient, and its designs and produces are under LabWindows/CVI environment, and this system is highly versatile and extendable and allows to be established flexibly and rapidly in accordance with different needs. The developed system has been successfully applied in training of a certain type of the tank, thereby increasing the simulation fidelity of the simulator as well as the coverage of the training sessions. Moreover, the development of this system will also provide powerful support for the system functions and performance evaluation. In the future, the further research on some training contents, such as the system operation and fault diagnosis and so on, can be carried out on this so as to meet the satisfy of the daily training, thereby enhancing the use and maintenance skills of the equipment and enabling the digitized new equipment to form combat effectiveness as soon as possible.

\section{REFERENCES}

[1] LIU Junhua. The tutorialof virtual instrument programming language LabWindows/CVI[M]. Beijing: Electronic industry press 2008.

[2] RONG Ming, CHANG Tian-qing, WANG Qin-zhao.The Design of Tank Embeded Training Simulation System [J] Fire Control and Command Control,2008, 33(2):128-130

[3] WANG Yong, XU Jian-ming. Simulation of Airborne Multi-function Display Based on $\mathrm{VC}++[\mathrm{J}]$. ElectronicsOptics \& Control, 2005, 12(3): 36-39.

[4] ZHAO Fang, YAN He-shun, HAN Liang. Design and Realization of Commander's Command Training Simulator for Digitized Tank[J].Journal of System Simulation, 2009, 9(21): 5727-5730.

[5] PENG Yan, XU Zeng-zeng, SHEN Lei.Missile test system based-on LabWindows/CVI[J]. Panel Technique,2006,35(3):6-8 